\title{
SIMULATION MODELS AND APPLICATIONS
}

\author{
KRAVARIKOVA, H[elena]
}

\begin{abstract}
Simulation is an experimental method in replacing the real system computer model. On this model it is possible to perform many experiments to evaluate them, be optimized and the results applied to real system. No exists other "method" or "theory" which would allow to experiment with complex systems before being put into operation. While it is known by another algorithm for the task model experiments in various fields of science and research, which would allow to solve various complicated processes using computer technology. Real experiments, in particular their preparation, are time consuming and very physical. In some cases they may not even realize and are not as flexible as computer models. Therefore, modeling and simulation is becoming an ideal tool for decision support of design and prediction of different types of structures, equipment and processes at different levels in the company

Key words: simulation model, prediction, stress, strain
\end{abstract}

\section{INTRODUCTION}

Using simulation models and analysis of the problem is realized in the field of technology fusion welding MAG. Fusion welding creates weld pool that solidifies and creates a physical connection required associated materials. Bond formed during cooling also strengthens the bond. It is in line with changes in physical and mechanical properties of metallic materials caused by temperature change. During the heating, melting and cooling of direct material, melt occurs during the welding process to various metallurgical processes. Their conduct may substantially affect the final performance of welded joints. These changes occur in the weld and near the welded joint in a so-called. The Heat Affected Zone (HAZ). HAZ area is very important mainly because of the strength of welded joints. HAZ most research area of thermal cycles and residual stresses affecting the strength of the weld.

\section{SIMULATION MODEL}

The simulation model is the nature of information solutions to the computer experiment. An estimate by deterministic methods of numerical analysis and model runs digital simulation solutions. Most employed method of solving the MKP.

The simulation model is always the same shape and dimensions to the real experimental sample respectively real part. To build the model for computer simulation in most cases is considered a 3-D model. Model system consists of three materials (basic materials, auxiliary materials and the surrounding environment). Base material and filler metal is considered as a solid with the same thermal and mechanical properties.

Heat from the arc to melt and additional basic material for the numerical simulation is defined as the volume of a moving heat source. Moving a volume heat source in the welding process can be entered in several ways. The most commonly used volumetric heat source distributed according to Gauss and by Goldak double ellipse.

To solve the numerical simulation of thermal cycles and residual stress in the weld and its surroundings is necessary to solve the thermal and voltage-strain job. Produced of simulation model (geometric model), it is necessary to define the thermo-physical and mechanical properties of the basic and additional material based on their chemical composition depending on temperature changes. To solve the task it is necessary to determine the appropriate mathematical model.

Thermal analysis dealt with the numerical simulation is considered as unsteady and nonlinear problems. Unsteady temperature field, where there is a large temperature change depending on the time change and the amount of energy supplied in the form of heat. For homogeneous and isotropic with a continuum characterization thermo-physical property of the material can be searched for the temperature field solution to use the Fourier - Kirchhoff's differential equation of heat conduction in the form:

$$
\frac{\partial T}{\partial t}=\frac{\lambda}{\rho . c}\left(\frac{\partial^{2} T}{\partial x^{2}}+\frac{\partial^{2} T}{\partial y^{2}}+\frac{\partial^{2} T}{\partial z^{2}}\right)+\frac{1}{\rho . c} \frac{\partial Q_{\mathrm{v}}}{\partial t}
$$

Equation (1) can be written in the form of tensors:

$$
\lambda T_{\mathrm{ii}}+\dot{Q}_{\mathrm{v}}=\rho . \dot{T}
$$

To solve the equation (1) are necessary conditions for uniqueness, which characterize the geometric shape of the weld simulation model, its material properties as well as initial and boundary conditions.

To solve the differential equations of heat conduction is a necessary and sufficient condition for determining the initial and boundary conditions. Initial conditions for numerical simulation correspond to actual conditions in which the welding process is carried out. For the simulation model of technological process of welding MAG apply boundary conditions III. type. The total heat flow during welding is the sum of densities of heat flow by convection, conduction and radiation. Heat flow in convection is expressed by Newton's law quench, which depends on the heat transfer coefficient $h\left[\mathrm{~W} \cdot \mathrm{m}^{-2} \cdot \mathrm{K}^{-1}\right]$.

Cooling of the heated material in technological process of welding can be expressed to the abovementioned boundary condition III. type:

$$
\lambda\left(\frac{\partial T}{\partial n}\right)_{\mathrm{s}}=h_{\mathrm{k}}\left(T_{\mathrm{s}}-T_{\mathrm{r}}\right)+\varepsilon \sigma_{0}\left(T_{\mathrm{s}}^{4}-T_{\mathrm{r}}^{4}\right)=\left(h_{\mathrm{k}}+h_{\mathrm{r}}\right)\left(T_{\mathrm{s}}-T_{\mathrm{r}}\right)=h_{\mathrm{c}}\left(T_{\mathrm{s}}-T_{\mathrm{r}}\right)
$$

For solve numerical simulation should be used finite element reflecting the quasi-static system, where the temperature is constant regardless of field position on the arc. (Taraba, 1999)

FEM solution heat tasks described by the differential equation (1) and (2) can be non-linear solution for the nodal temperature $T$ written in the form of matrix:

$$
\left[C_{\mathrm{T}}\right]\{\dot{T}\}+\left[K_{\mathrm{T}}\right]\{T\}=\{\dot{\mathrm{Q}}\}
$$


On the basis of the law of conservation of energy is assumed equivalence of heat and mechanical energy and thus the connection of thermal and mechanical field (i.e. the temperature field and thermal stress field). The basic equation of thermomechanics for elastic - viscoplastic continuum can be written in the form:

$$
c . \rho \dot{T}+\dot{q}_{\mathrm{ii}}=\dot{Q}_{\mathrm{v}}-\frac{E \cdot \alpha \cdot T}{1-2 v} \dot{\varepsilon}_{\mathrm{ii}}+\xi \sigma_{\mathrm{dij}} \dot{\varepsilon}_{\mathrm{vpij}}
$$

The total strain $\mathrm{d} \varepsilon_{\mathrm{ij}}$ is composed of elastic strain $\mathrm{d} \varepsilon_{\mathrm{eij}}$, conventional plastic strain $\mathrm{d} \varepsilon_{\mathrm{pij}}$, plastic strain from transformation plasticity $\mathrm{d} \varepsilon_{\mathrm{tpij}}$, thermal strain $\mathrm{d} \varepsilon_{\mathrm{Tij}}$ and transformation strain $\mathrm{d} \varepsilon_{\text {trij }}$ :

$$
\mathrm{d} \varepsilon_{\mathrm{ij}}=\mathrm{d} \varepsilon_{\mathrm{eij}}+\mathrm{d} \varepsilon_{\mathrm{pij}}+\mathrm{d} \varepsilon_{\mathrm{tpij}}+\mathrm{d} \varepsilon_{\mathrm{Tij}}+\mathrm{d} \varepsilon_{\mathrm{trij}}
$$

Mathematical model for thermoelastic-plastic continuum equation can be written in the form of matrix:

$$
\{\mathrm{d} \sigma\}=[D]\{\mathrm{d} \varepsilon\}+\mathrm{d} C^{*}\left\{\sigma_{\mathrm{d}}\right\}-M^{*}\left\{\mathrm{~d} \varepsilon_{\mathrm{T}}\right\}
$$

Initial and boundary conditions for the elastic - plastic mathematical model determines the mechanical properties of the material and degrees of freedom. (Rodaj, 1992)

Material model is considered as linear or bilinear model with kinematic reinforcement. Calculation of numerical simulation is implemented as non-stationary and nonlinear state with continuous accumulation of tension.

Instant tension states are displayed as spatial fields Mises equivalent stress (MPa), which gives a picture of the intensity of stress in materials

\section{PRESENTATION OF RESULTS}

As a result of thermal analysis technology MAG welding process is running temperature fields depending on the time of welding. The result is a solution to the tasks arising in the course weld voltage during welding as well as residual stress, which in weld remain after cooling to room temperature. It is also possible to observe the simulation of deformation occurring in the welding process and the resulting cooling of the weld.

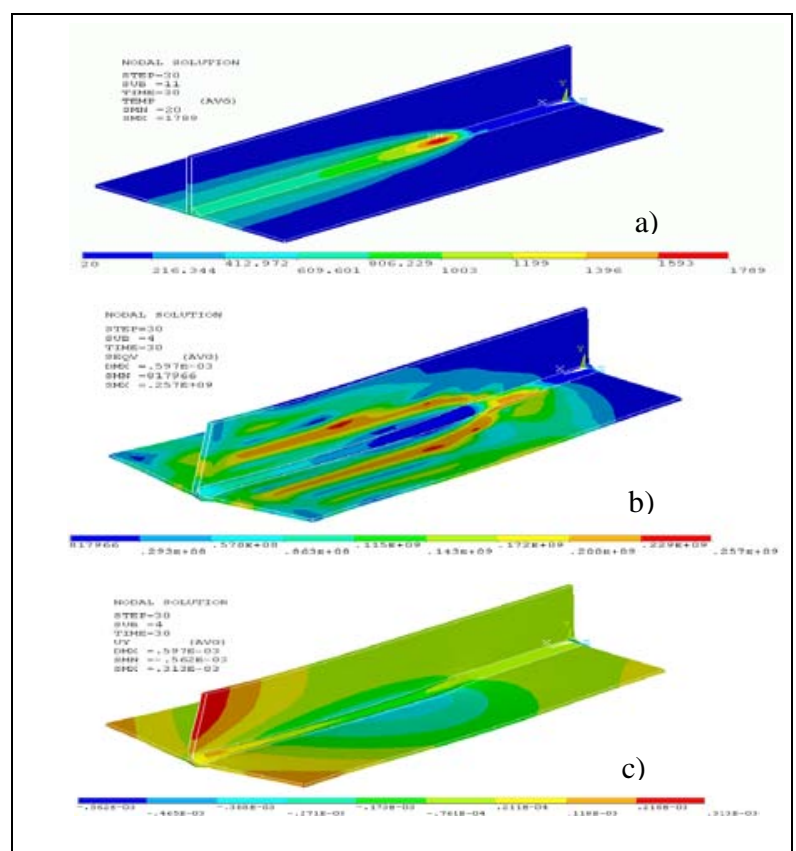

Fig. 1. At the time of $30 \mathrm{~s}$ a) Course of temperature fields, b) Course Mises stress, c) Course deformation fields (Žibrická, 2003)
In Fig. 1 a) shows the course of temperature fields of a moving volume source of heat in the early $30 \mathrm{~s}$ when welding. At that time, the minimum temperature welding material has $20^{\circ} \mathrm{C}$. Maximum temperature is $1635^{\circ} \mathrm{C}$ in the concentrated heat source, where melting occurs and the mixing of basic and auxiliary materials. In Fig. 1 b) shows the course Mises stress at the time of $30 \mathrm{~s}$ from the start of welding. At the end of the weld stress is smallest, because heated molten metal has a low modulus. In Fig. 1 c) shows the maximum deformation $0.313 \mathrm{~mm}$ and the minimum $-0.562 \mathrm{~mm}$. Deformation values are relatively small, because there does not temperature in welding material.

\section{EVALUATION OF RESULTS}

The results obtained by numerical simulation given a relatively objective picture of the behavior of the basic material and additional material under the influence of the effect of arcing. Show by the formation of temperature and velocity field in the welding process. The results of computer simulations were used to illustrate the welding process and thus to evaluate the physical and metallurgical processes in the welding MAG. Of course, that the purpose of simulation is to predict the optimum welding parameters and conditions, and thus speed up and improve the process. Based on computer simulations it is possible to optimize the welding parameters. Achievements of the thermo-elasto-plastic analysis using the simulation prediction stress conditions that arise in the welding process, while the distribution of residual stress after welding. The results are useful in industrial practice.

\section{CONCLUSION}

To use the example simulation model for welding can be concluded that simulation models are complex to use in tackling a variety of disciplines themselves as real experiments. In addressing the challenges of using simulation models and their solution using the FEM is the expertise needed to tackle the mathematical and computer proficiency. Based on these attributes it is possible to address complex processes to arrive at concrete conclusions Tor and applicable in practice.

\section{ACKNOWLEDGEMENTS}

This paper was supported by projects VEGA 1/0389/11.

\section{REFERENCES}

Kuncipál, J., et al . (1986). Teórie svařováni (Welding theory). Praha: SNTL/ALFA. $365 \mathrm{~s}$

Országh, P., Országh, V. (2000). Zváranie MIG/MAG ocelí a neželezných kovov (Welding MIG / MAG welding of steels and nonferrous metals). Bratislava: Polygrafia SAV. $460 \mathrm{~s}$. ISBN 80-88780-36-5

Rodaj, D. (1992). Heat Effects of Welding.Berlin Heidelberg

Taraba, B., Behúlová, M., Kraváriková, H. (1999). Mechanika tekutín, Termomechanika (Fluid Mechanics, Thermodynamics). Bratislava: STU. 241 s. ISBN 80-2271265-5

Tso - Liang, T.; Peng - Hsiang, C. \& Wen - Cheng, T. (2002). Effect of welding sequences on residual stresses. In computers and Structures. roč. 11

Žibrická, M. (2003). Deformácie kútového zvarového spoja (Deformation corners welded joints). Diplomová práca (Thesis) MTF STU 